\title{
Quantitative and Qualitative Changes in Sugar Content of Peach Genotypes [ Prunus persica (L.) Batsch.]
}

\author{
Sylvia J. Brooks', James N. Moore ${ }^{2}$, and J. Brad Murphy ${ }^{3}$ \\ Department of Horticulture and Forestry, University of Arkansas, Fayetteville, AR 72701 \\ Additional index words. sucrose, glucose, fructose, sorbitol, fruit breeding, Prunus persica
}

\begin{abstract}
Fruit of four clingstone peach [Prunus persica (L.) Batsch.] seedling populations, 54 advanced selections, and the cultivars Allgold and Goldilocks were analyzed for sugar content, soluble solids concentration (SSC), and acidity. Sucrose, glucose, fructose, and sorbitol were identified and quantified by high pressure liquid chromatography (HPLC) analysis. Variation was found for all the sugars between the seedling populations. Comparison of the means for the advanced selections with 'Goldilocks' indicates that progress has already been made toward selection for a sweeter peach. Glucose, fructose, sorbitol, SSC, and acidity (citric) differed significantly for two harvest years, while sucrose and total sugar concentrations showed no significant yearly variation. A fruit maturity study revealed no significant changes in SSC, percentages of glucose, fructose, and total sugar during ripening on the tree. Acidity and percent sorbitol decreased, while the sugar : acid ratio and percent sucrose increased with increasing maturity. Broadsense heritability of SSC, acidity, and sugar : acid ratio bad values >0.72, while values for individual sugars and total sugars were much lower. Transgressive segregation for each sugar was found in seedling populations.
\end{abstract}

Consumer concerns about additives in processed food products are stimulating processors to develop "all natural-nothing added" products. A recent objective of the Arkansas peach breeding program is to develop processing peach cultivars with higher levels of natural sugars to obviate the necessity of adding sugars during processing.

Most studies (Allen, 1932; Bigelow and Gore, 1905; Culpepper and Caldwell, 1930; Deshpande and Salunkhe, 1964; Haller and Harding, 1939; Moriguchi et al., 1990; Nightingale et al., 1930; Robertson and Meredith, 1988; Sweeney et al., 1970; Thompson and Whittier, 1912; Wrolstad and Shallenberger, 1981) have shown that the major sugar in ripe peach fruit is sucrose, followed by the reducing sugars (glucose and fructose), and lower amounts of sorbitol (Moriguchi et al., 1990; Robertson and Meredith, 1988; Wrolstad and Shallenberger, 1981). Trace amounts of maltose, galactose, and xylose have also been reported (Wrolstad and Shallenberger, 1981). Fructose has been reported to be sweeter than sucrose by as much as 1.8 times (Doty, 1976), while glucose is reported to be less sweet than sucrose (Pangborn, 1963; Yamaguchi et al., 1970). Robertson and Meredith (1988) found that "high-quality" peaches contained a higher percentage of fructose and lower percentages of glucose and sorbitol than "low-quality peaches." Sugar content and SSC of peaches are known to be influenced by position of the fruit in the canopy (Dann and Jerie, 1988; Marini, 1985), crop load (Culpepper and Caldwell, 1930; Marini, 1985), pruning practices (Coe, 1933), and yearly climate (Culpepper and Caldwell, 1930; Haller and Harding, 1939; Sweeney et al., 1970).

Received for publication 3 Apr. 1992. Accepted for publication 15 Aug. 1992. Published with approval of the Director, Arkansas Agricultural Experiment Station. This research funded in part by a grant from Gerber Products Co., Fremont, Mich., and Ft. Smith, Ark. We thank Ronald W. McNew, Agricultural Statistics Lab, for conducting statistical analyses. The cost of publishing this paper was defrayed in part by the payment of page charges. Under postal regulations, this paper therefore must be hereby marked advertisement solely to indicate this fact.

'Graduate Assistant. Current address: Fruit Crops Dept., Univ. of Florida, Gainesville, FL 32611.

${ }^{2}$ Distinguished Professor.

${ }^{3}$ Associate Professor.
This study was undertaken to: 1) identify and quantify sugars present in peach fruit in seedlings and selections in the Arkansas breeding program, 2) determine year-to-year variations in sugar content of selected genotypes, 3) examine the change in concentration of individual sugars as fruits mature from the maturegreen to the full-ripe stage on the tree, and 4) estimate heritability of sugar content for peach breeding.

\section{Materials and Methods}

This study involved sugar analysis of fruit from four peach seedling populations (average of 39 trees per population) and 54 clonal selections in the Arkansas breeding program. 'Goldilocks' was also included as it is an important commercial cultivar grown in Arkansas for processing into baby food. 'Allgold' and selection A-219 were used for a study of sugar changes during maturation.

Fruit was harvested in 1988 from trees located at the Univ. of Arkansas Fruit Substation, Clarksville, Ark. In 1989, seedling population 8302 was again harvested along with its parents (A-18 and A-175). The two harvests of seedling population 8302 were used to determine year-to-year variation in sugar content. Clemson color chips were used to determine stage of ripeness of the fruit (Delwiche and Baumgardner, 1985). Peaches for the sugar content study were harvested at the firm-ripe stage as determined by Clemson color-chip \#6. A minimum of nine peaches was harvested for each tree from its periphery at a height of $\approx 1.5 \mathrm{~m}$.

Peaches for the fruit maturity study were harvested at Clemson color-chip \#1, \#3, and \#6 along with peaches at a pre-1 stage and a post- 6 stage. A peach was classified as pre- 1 when it was greener than the \#l color-chip. A post-6 peach was one that was more yellow than the \#6 color-chip, but was still slightly green along the suture. Five trees each of 'Allgold' and A-219 were harvested.

All peaches were frozen immediately after harvest to facilitate transport to the Univ. of Arkansas at Fayetteville and stored frozen until analysis.

HPLC was used to identify and quantify the sugars in the

Abbreviation: SSC, soluble solids concentration. 
Table 1. Ranges of sugar content, SSC, acidity, and sugar : acid ratio of fruit from 54 Arkansas peach selections ${ }^{2}$ in comparison with the standard, 'Goldilocks'.

\begin{tabular}{lcccc}
\hline \hline Variable & High & Low & $\begin{array}{c}\text { Mean of } \\
\text { 54 selections }\end{array}$ & 'Goldilocks' \\
\hline Sucrose(\%)y & $3.67(\mathrm{~A}-266)$ & $1.12(\mathrm{~A}-364)$ & 2.21 & 2.18 \\
Glucose(\%)y & $2.25(\mathrm{~A}-208)$ & $0.71(\mathrm{~A}-373)$ & 1.40 & 1.19 \\
Fructose(\%) & $2.59(\mathrm{~A}-208)$ & $0.62(\mathrm{~A}-252)$ & 1.61 & 1.37 \\
Sorbitol(\%)y & $1.50(\mathrm{~A}-207)$ & $0.24(\mathrm{~A}-1)$ & 0.42 & 0.36 \\
Total sugar(\%)y & $8.32(\mathrm{~A}-266)$ & $3.90(\mathrm{~A}-188)$ & 5.64 & 11.5 \\
SSC $(\%)^{\mathrm{y}}$ & $22.5(\mathrm{~A}-207)$ & $10.5(\mathrm{~A}-188)$ & 13.0 & 0.25 \\
Acidity (\% citric) & $1.15(\mathrm{~A}-207)$ & $0.22(\mathrm{~A}-320)$ & 0.47 & 47.1 \\
Sugar : acid ratio & $71.6(\mathrm{~A}-320)$ & $12.6(\mathrm{~A}-208)$ & 30.9 & \\
\hline
\end{tabular}

${ }^{2}$ Selection numbers in parentheses.

y Percent fresh weight.

Table 2. Sugar content of segregating seedling populations of peach.

\begin{tabular}{|c|c|c|c|c|c|}
\hline & Sucrose & Glucose & Fructose & Sorbitol & $\begin{array}{l}\text { Total } \\
\text { sugars }\end{array}$ \\
\hline Population & \multicolumn{5}{|c|}{ Fresh wt $(\%)$} \\
\hline 8302 & $3.19 c^{z}$ & $2.05 \mathrm{c}$ & $2.27 \mathrm{~b}$ & $0.72 \mathrm{~b}$ & $8.23 c$ \\
\hline 8319 & $2.17 \mathrm{a}$ & $1.56 \mathrm{a}$ & $1.74 \mathrm{a}$ & $0.56 \mathrm{a}$ & $6.57 \mathrm{a}$ \\
\hline 8320 & $2.93 \mathrm{~b}$ & $1.76 \mathrm{~b}$ & $1.85 \mathrm{a}$ & $0.67 \mathrm{ab}$ & $7.22 \mathrm{~b}$ \\
\hline 8405 & $3.24 \mathrm{c}$ & $1.69 \mathrm{ab}$ & $1.85 \mathrm{a}$ & $1.28 \mathrm{c}$ & $7.95 \mathrm{c}$ \\
\hline
\end{tabular}

${ }^{\mathrm{z}}$ Mean separation within columns by $t$ test $(P=0.05)$.

Table 3. SSC, acidity, and sugar : acid ratio of segregating seedling populations of peach.

\begin{tabular}{lccc}
\hline \hline Population & SSC $(\%)$ & $\begin{array}{c}\text { Acidity } \\
(\% \text { citric })\end{array}$ & Sugar : acid \\
\hline 8302 & $13.0 \mathrm{~b}^{\mathrm{z}}$ & $0.48 \mathrm{~b}$ & $28.3 \mathrm{a}$ \\
8319 & $12.0 \mathrm{a}$ & $0.43 \mathrm{a}$ & $29.5 \mathrm{a}$ \\
8320 & $15.5 \mathrm{~d}$ & $0.41 \mathrm{a}$ & $39.4 \mathrm{~b}$ \\
8405 & $13.5 \mathrm{c}$ & $0.53 \mathrm{~b}$ & $26.7 \mathrm{a}$ \\
\hline
\end{tabular}

${ }^{2}$ Mean separation within columns by $t$ test $(P=0.05)$.

fruits, according to Lingle and Dunlap (1987). Nine peaches were divided into three samples consisting of three peaches each. One core was removed from the equator of each peach opposite the suture. The three cores making up a sample were combined and then ground in a laboratory blender with $1 \mathrm{ml}$ of cold 50 mu K-phosphate ( $\mathrm{pH} 7.5$ ) buffer/g fresh weight. The puree was centrifuged at $15,000 \mathrm{x} g$ at $4 \mathrm{C}$ for $15 \mathrm{~min}$. The resulting supernatant was filtered through a $0.45 \mu \mathrm{m}$ nylon 66 filter (Schleicher and Schuell, Keene, N.H.). The filtrate was frozen for HPLC analysis at a later date.

Just before HPLC analysis, the filtrate was thawed. Sugars were separated using a Benson carbohydrate $\mathrm{BC}-100 \mathrm{Ca}^{++}$column (Alltech, Deerfield, Il.) maintained at 85C. The solvent was distilled-deionized water at a flow rate of $1.0 \mathrm{ml} \cdot \mathrm{min}^{-1}$. A 2- $\mu$ l sample was injected into the HPLC for analysis. Sucrose, glucose, fructose, and sorbitol were identified and quantified by comparison with peaks produced by a known standard sugar solution. A fifth peak that eluted before the sucrose peak was not identified. It was determined that the peak could not have been produced by raffinose, stachyose, maltose, or maltotriose.

SSC was determined for each peach and each combined sample using a table top refractometer (Erma, Tokyo, Japan). Titratable acidity was determined for each sample using $0.1 \mathrm{~N}$ $\mathrm{NaOH}$ with an endpoint of $\mathrm{pH}$ 7.0. and converted to percent citric acid. From these data, the sugar : acid ratios were calculated.

Broad-sense heritability was calculated for the seedling populations and the advanced selections. Only one tree of each genotype was available for harvest for this study. Three samples were taken from each tree. The total variation for a trait was partitioned into among and within trees. An estimate of upperlimit for broad sense heritability was obtained by dividing the variance component for trees by the sum of the tree and within tree components.

The data were analyzed using the statistical analysis system (SAS) for personal computers. Means were compared by t-tests using the PDIFF option of LSMeans statement in PROC GLM of SAS. Differences were declared significant if $P \geq 0.05$. Analysis of variance showed no difference for SSC measurements between the individual measurements within a sample and the combined measurement for a sample.

\section{Results and Discussion}

Variation was found for all the variables measured on the advanced selections. 'Goldilocks' was below the mean of the advanced selections for all of the individual sugars and total sugars (Table 1). This difference indicates that progress has already been made toward selection for a peach with a higher sugar content. Selection A-266 had the highest percent sucrose at $3.67 \%$ and the highest percent total sugar at $8.32 \%$, which were much higher than the mean of all advanced selections ( $2.21 \%$ for sucrose and $5.64 \%$ for total sugars). A-208 had the highest percentage of glucose and fructose. A-207, at $1.50 \%$, had almost a 4-fold higher level of sorbitol than the group mean.

'Goldilocks' was below the general mean for SSC and acidity (Table 1), with its sugar : acid ratio $\approx 50 \%$ higher than the overall mean. A-320 had the highest sugar : acid ratio at 71.6, and the lowest acidity at $0.22 \%$.

A-207 and A-208 had the highest acidity. These are nonmelting nectarines resulting from hybridization of canning clingstone peaches and nectarines. The exceptionally high acidity of these selections may indicate an inherent difference between peach and nectarine.

Significant variation was found among the seedling populations for all the characteristics measured (Tables 2 and 3). Fructose had the least amount of variation, with only population 8302 being significantly different from the other populations. When averaged across the populations, sucrose accounted for $\approx 40 \%$ of the total sugar, glucose and fructose were each about $25 \%$, and sorbitol made up the remaining $10 \%$.

There were significant differences between all the populations 

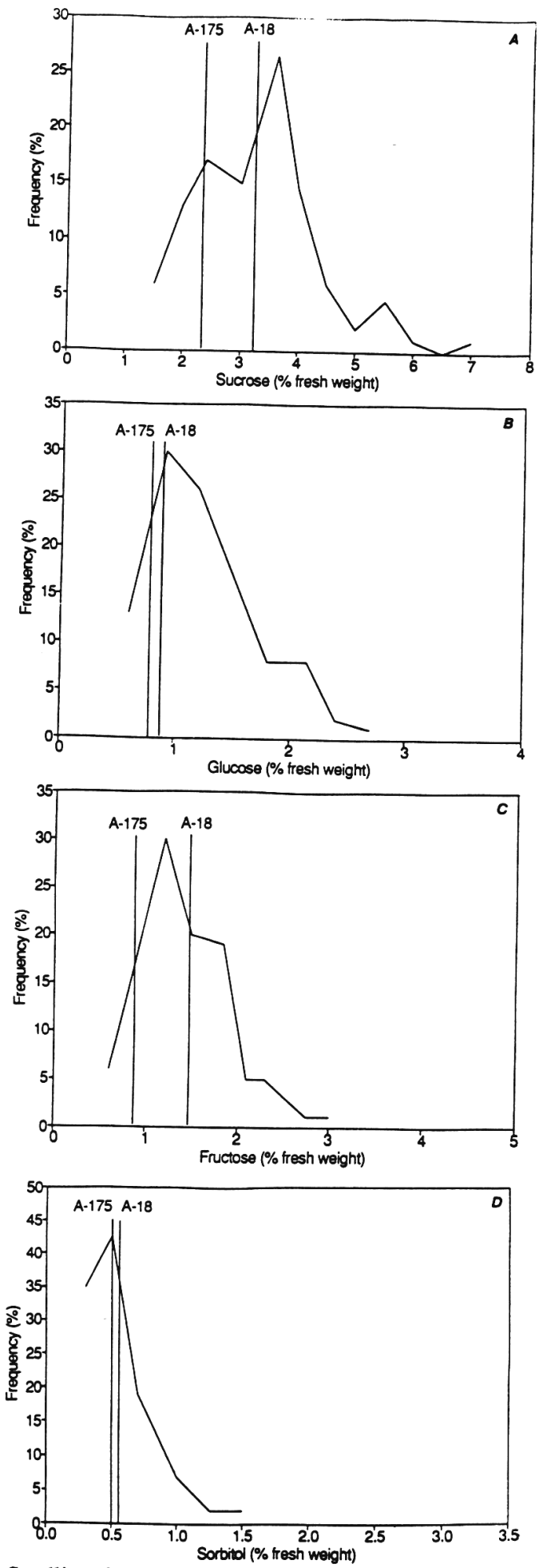

Fig. 1. Seedling frequency curves for percent sucrose (A), glucose (B), fructose (C), and sorbitol (D) for peach population 8302 and its parents $A-18$ and $A-175$

for SSC (Table 3). There was less variability for acidity and the sugar : acid ratio. Population 8320 had the highest SSC and sugar : acid ratio.

Sugar content of seedling trees in population 8302 was compared to the parent trees in 1989. The seedling population had individuals with a higher percentage of each individual sugar
Table 4. Variation in SSC, acidity, and sugar : acid ratio in peach seedling population 8302 between 2 years.

\begin{tabular}{lccc}
\hline \hline Year & SSC $(\%)$ & $\begin{array}{c}\text { Acidity } \\
(\% \text { citric })\end{array}$ & Sugar : acid \\
\hline 1988 & $13.0 \mathrm{~b}^{\mathbf{z}}$ & $0.48 \mathrm{a}$ & $28.5 \mathrm{~b}$ \\
1989 & $11.0 \mathrm{a}$ & $0.66 \mathrm{~b}$ & $16.7 \mathrm{a}$ \\
\hline
\end{tabular}

${ }^{2}$ Mean separation within columns by $t$ test $(P=0.05)$.

Table 5. Variation in concentration of individual sugars in peach seedling population 8302 between 2 years.

\begin{tabular}{llcccc}
\hline \hline & Sucrose & Glucose & Fructose & Sorbitol & $\begin{array}{c}\text { Total } \\
\text { sugars }\end{array}$ \\
\cline { 2 - 6 } Year & \multicolumn{5}{c}{ Fresh wt (\%) } \\
\hline 1988 & $3.18 \mathrm{a}^{\mathrm{z}}$ & $2.03 \mathrm{~b}$ & $2.25 \mathrm{~b}$ & $0.72 \mathrm{~b}$ & $8.18 \mathrm{a}$ \\
1989 & $3.20 \mathrm{a}$ & $1.24 \mathrm{a}$ & $1.39 \mathrm{a}$ & $0.50 \mathrm{a}$ & $6.33 \mathrm{a}$ \\
\hline
\end{tabular}

${ }^{z}$ Mean separation within columns by $t$ test $(P=0.05)$.

Table 6. Effect of stage of maturity on SSC, acidity, and sugar : acid ratio of peach (combined means of 'Allgold' and A-219).

\begin{tabular}{lccc}
\hline \hline $\begin{array}{c}\text { Stage of } \\
\text { maturity }\end{array}$ & SSC (\%) & $\begin{array}{c}\text { Acidity } \\
\text { (\% citric) }\end{array}$ & Sugar : acid \\
\hline Pre-1 & $11.0 \mathrm{a}^{\mathrm{y}}$ & $0.62 \mathrm{~d}$ & $17.7 \mathrm{a}$ \\
1 & $11.0 \mathrm{a}$ & $0.55 \mathrm{c}$ & $20.2 \mathrm{~b}$ \\
3 & $11.0 \mathrm{a}$ & $0.58 \mathrm{c}$ & $18.9 \mathrm{ab}$ \\
6 & $11.5 \mathrm{a}$ & $0.44 \mathrm{~b}$ & $25.9 \mathrm{c}$ \\
Post-6 & $11.5 \mathrm{a}$ & $0.39 \mathrm{a}$ & $29.5 \mathrm{~d}$ \\
\hline
\end{tabular}

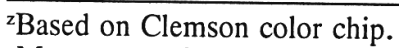

yMean separation within columns by $t$ test $(P=0.05)$.

Table 7. Effect of stage of maturity on concentration of sugars in peach fruits (combined means of 'Allgold' and A-219).

\begin{tabular}{llllll}
\hline \hline $\begin{array}{c}\text { Stage of } \\
\text { maturity }\end{array}$ & Sucrose & Glucose & Fructose & Sorbitol & $\begin{array}{c}\text { Total } \\
\text { sugar }\end{array}$ \\
\hline Pre-1 & $2.47 \mathrm{a}^{\mathrm{y}}$ & $1.39 \mathrm{a}$ & $1.51 \mathrm{a}$ & $0.54 \mathrm{~b}$ & $5.91 \mathrm{a}$ \\
1 & $2.41 \mathrm{a}$ & $1.30 \mathrm{a}$ & $1.46 \mathrm{a}$ & $0.64 \mathrm{~b}$ & $5.80 \mathrm{a}$ \\
3 & $2.47 \mathrm{a}$ & $1.23 \mathrm{a}$ & $1.30 \mathrm{a}$ & $0.38 \mathrm{a}$ & $5.39 \mathrm{a}$ \\
6 & $3.56 \mathrm{~b}$ & $1.28 \mathrm{a}$ & $1.44 \mathrm{a}$ & $0.38 \mathrm{a}$ & $6.65 \mathrm{a}$ \\
Post-6 & $3.28 \mathrm{~b}$ & $1.08 \mathrm{a}$ & $1.24 \mathrm{a}$ & $0.39 \mathrm{a}$ & $5.98 \mathrm{a}$ \\
\hline
\end{tabular}

${ }^{2}$ Based on Clemson color chip.

${ }^{y}$ Mean separation within columns by $t$ test $(P=0.05)$.

Table 8. Broad-sense heritability (percent) of sugar and acid concentrations for peach seedling populations and advanced selections.

\begin{tabular}{lcc}
\hline \hline Characteristic & $\begin{array}{c}\text { Seedling } \\
\text { populations }\end{array}$ & $\begin{array}{c}\text { Advanced } \\
\text { selections }\end{array}$ \\
\hline SSC (\%) & 72.5 & 77.3 \\
Acidity (\% citric) & 79.1 & 96.2 \\
Sugar : acid ratio & 76.2 & 88.8 \\
Sucrose (\%) & 26.1 & 36.6 \\
Glucose (\%) & 21.6 & 33.5 \\
Fructose (\%) & 28.1 & 40.4 \\
Sorbitol (\%) & 49.2 & 77.6 \\
Total sugar (\%) & 22.0 & 20.5 \\
\hline
\end{tabular}

${ }^{\mathrm{z}}$ Average of populations $8302,8319,8320$, and 8405 .

than either parent (Fig. 1). Such transgressive segregation indicates that it should be possible to select individual seedlings in a segregating population with higher sugar content than contained by either parental genotype. 
Year-to-year variations in sugar and acid content were evaluated for seedling population 8302. SSC, acidity, sugar : acid ratio (Table 4) and percent glucose, fructose, and sorbitol (Table 5) differed significantly between the two harvest years. The percentage of sucrose did not show yearly variation, suggesting that sucrose content is influenced less by environmental variables than the other forms of sugar. There was also no significant difference in percent total sugar. Year-to-year variation in the percentage of sugar may be explained by the differences in climate and crop load between the 2 years. Culpepper and Caldwell (1930) determined that these were the most important factors in year-to-year differences in sugar content of peach.

A maturity study was conducted with 'Allgold' and selection A-219 to determine changes in sugars as the fruit ripened on the tree. Since no significant genotype interactions were found, the data for the two genotypes were combined. SSC did not change significantly from the pre- 1 stage through the post- 6 stage of maturity (Table 6). Acidity showed a gradual decrease with advancing maturity and the sugar : acid ratio showed a significant increase with increased maturity. This result indicates that the increase in perceived sweetness of the peach as it ripens is due to a decrease in acidity rather than an increase in SSC.

Sucrose was the major sugar at all stages of fruit maturity (Table 7). Other studies (Bigelow and Gore, 1905; Moriguchi et al., 1990; Nightingale et al., 1930; Thompson and Whittier, 1912) have found that sucrose is the major sugar in mature peach fruits, but that the concentration of reducing sugars (fructose and glucose) is higher in immature fruit. The percentage of sucrose showed no significant change from the pre-1 stage through stage 3 (Table 7). Between stage 3 and stage 6 there was a significant increase in sucrose, with no further significant changes occurring through the post- 6 stage. Sucrose accounted for $42 \%$ of the total sugar at the pre-1 stage and increased to $55 \%$ in the post-6 stage.

The percentage of sorbitol did not change significantly from pre-1 to stage 1 (Table 7), but a significant decrease occurred between stages 1 and 3. For the remainder of the ripening period there were no significant changes. Sorbitol decreased from $9.1 \%$ of total sugars at stage 1 to $6.5 \%$ at maturity. Moriguchi et al. (1990) reported that the concentrations of sorbitol remained constant at $4 \%$ of the total sugar throughout maturation.

The percentage of glucose, fructose, and total sugar did not change significantly throughout ripening. This finding agrees with findings for glucose and fructose by Moriguchi et al. (1990).

Broad-sense heritability for sugar and acid components were calculated for the seedling populations and the advanced selections (Table 8). Only one tree of each genotype was available for harvest; therefore, the environmental variability likely was underestimated. These values are useful as they give an estimate of maximum heritability. The heritability for SSC, acidity, and sugar : acid ratio were all fairly high $(>0.72)$. This value indicates that it should be possible to select for these character- istics based on plant phenotype. The heritabilities for the individual sugars and percent total sugar were lower. Despite these low values, there is enough variation present that genetic advance should be possible. The transgressive segregation that was found for all the sugars also indicates that it is possible to select for high sugar content in most segregating peach seedling populations.

\section{Literature Cited}

Allen, F.W. 1932. Physical and chemical changes in the ripening of deciduous fruits. Hilgardia 6:381-441.

Bigelow, W.D. and H.C. Gore. 1905. Studies on peaches. U.S. Dept. Agr. Bur. Chem. Bul. 97.

Coe, F.M. 1933. Peach harvesting studies. Utah Agr. Expt. Sta. Bul. 241.

Culpepper, C.W. and J.S. Caldwell. 1930. The canning quality of certain commercially important eastern peaches. U.S. Dept. Agr. Tech. Bul. 196.

Dann, I.R. and P.H. Jerie. 1988. Gradients in maturity and sugar levels of fruit within peach trees. J. Amer. Soc. Hort. Sci. 113:27-31.

Delwiche, M.J. and R.A. Baumgardner. 1985. Ground color as a peach maturity index. J. Amer. Soc. Hort. Sci. 110:53-57.

Deshpande, P.B. and D.K. Salunkhe. 1964. Effects of maturity and storage on certain biochemical changes in apricots and peaches. Food Technol. 18:85-88.

Doty, T.E. 1976. Fructose sweetness: A new dimension. Cereal Foods World 21(2):62-63.

Haller, M.H. and P.L. Harding. 1939. Effect of storage temperatures on peaches. U.S. Dept. Agr. Tech. Bul. 680.

Lingle, S.E. and J.R. Dunlap. 1987. Sucrose metabolism in netted muskmelon fruit during development. Plant Physiol. 84:386-389.

Marini, R.P. 1985. Vegetative growth, yield, and fruit quality of peach as influenced by dormant pruning, summer pruning, and summer topping. J. Amer. Soc. Hort. Sci. 110:133-139.

Moriguchi, T, T. Sanada, and S. Yamaki. 1990. Seasonal fluctuations of some enzymes relating to sucrose and sorbitol metabolism in peach fruit. J. Amer. Soc. Hort. Sci. 115:278-281.

Nightingale, G.T., R.M. Addoms, and M.A. Blake. 1930. Development and ripening of peaches as correlated with physical characteristics, chemical composition, and histological structure of the fruit flesh: III. Macrochemistry. New Jersey Agr. Expt. Sta. Bul. 494:116.

Pangborn, R.M. 1963. Relative taste intensities of selected sugars and organic acids. J. Food Sci. 28:726-733.

Robertson, J.A. and F.I. Meredith. 1988. Characteristics of fruit from high- and low-quality peach cultivars. HortScience 23:1032-1034.

Sweeney, J.P., V.J. Chapman, and P.A. Hepner. 1970. Sugar, acid, and flavor in fresh fruits. J. Amer. Diet. Assn. 57:432-435.

Thompson, F. and A.C. Whittier. 1912. Forms of sugar found in common fruits. Proc. Amer. Soc. Hort. Sci. 9:16-22.

Wrolstad, R.E. and R.S. Shallenberger. 1981. Free sugars and sorbitol in fruits-a compilation from the literature. J. Assn. Offic. Anal. Chem. 64:91-103.

Yamaguchi, S., T. Yoshikawa, S. Ikeda, and T. Ninomiya. 1970. Studies on the taste of some sweet substances. part I. Measurement of the relative sweetness. Agr. Biol. Chem. 34:181-186. 